\title{
Gambaran Pengetahuan Remaja Putri Kelas VIIA dan B Tentang Personal Hygiene di SMPN 2 Mojo Kabupaten Kediri
}

Lely Khulafa'ur $\mathbf{R}^{1}$

${ }^{1}$ Akademi Kebidanan Dharma Husada Kediri Jawa Timur

\begin{abstract}
Abstrak
Kebanyakan remaja putri kurang memahami dan memperhatikan tentang personal hygiene dalam kehidupan sehari-hari.Perawatan personal hygiene yang salah dapat memicu berkembangnya kuman dan penyakit. Penelitian ini bertujuan untuk mengetahui Gambaran pengetahuan Remaja Putri Kelas VIIA dan B tentang personal hygienedi SMPN 2 Mojo Kabupaten Kediri.

Penelitian ini menggunakan desain Deskriptif dengan pendekatan cross sectional. Populasi dalam penelitian ini adalah semua remaja putri kelas VII A dan B dengan menggunakan teknik total sampling didapatkan sampel sejumlah 37 responden. Variabel Tunggal yaitu pengetahuan remaja putri tentang personal hygiene.Instrumen penelitian menggunakan kuesioner, kemudian data diolah melalui editing, coding, scoring, tabulating lalu analisis data dengan Persentase.

Hasil penelitian dari 37 responden didapatkan pengetahuan cukup sejumlah 21 responden (56\%).Pengetahuan tentang Pengertian personal hygienesejumlah 33 responden $(89,2 \%)$ dengan kriteria baik, Pengetahuan tentangTujuan personal hygiene dengan kriteria cukup berjumlah 17 responden $(49,9 \%)$, Pengetahuan tentangFaktor yang mempengaruhi personal hygiene dengan kriteria cukup berjumlah 20 responden $(54,1 \%)$, Pengetahuan tentangPrinsip personal hygiene berjumlah 19 responden $(51,4 \%)$ dengan kriteria cukup, Pengetahuan tentang dampak yang timbul pada masalah personal hygiene dengan kriteria cukup berjumlah 17 responden $(45,9 \%)$

Masih banyak remaja putri berpengetahuan cukup sehingga diperlukan peningkatan pengetahuan tentang personal hygiene dari pihak sekolah guna meningkatkan pengetahuan dan kesadaran remaja putri akan pentingnya personal hygiene, diharapkan dengan pengetahuan yang cukup remaja putri mampu melakukan personal hygiene.
\end{abstract}

Kata Kunci :Pengetahuan, Personal Hygiene, Remaja Putri

Korespondensi: Jl.Teratai RT 20RW 02 Kel.Ngampel Kec.Mojoroto Kota Kediri HP:0855664425144 ,email:iffat.yakta@gmail.com 


\section{Pendahuluan}

Personal hygiene merupakan perawatan diri, dimana seseorang merawat fungi-fungi tertentu seperti mandi, toileting, kebersihan tubuh secara umum dan berhias.Personalhygiene atau kebersihan diri diperlukan untuk kenyamanan, keamanan dan kesehatan seseorang, yang merupakan langkah awal mewujudkan kebersihan diri.Dengan tubuh yang bersih meminimalkan resiko seseorang terhadap kemungkinan terjangkitnya suatu penyakit yang berhubungan dengan kebersihan diri yang buruk. (Suryono, 2011:1)

Masa remaja adalah masa yang paling indah, tentunya akan terwujud apabila para remaja memiliki kesehatan yang baik. Masa ini merupakan tahap perkembangan transisi yang membawa individu dari masa kanak-kanak ke masa dewasa yang ditandai dengan perubahan fisik pada masa pubertas, serta perubahan kognitif dan sosial.Periode remaja umumnya dimulai sekitar 11 smpai 20 tahun.Sebagai generasi penerus bangsa, para remaja diharapkan memiliki kesehatan yang optimal, baik secara fisik, mental maupun sosialnya.Pada umumnya, masalah kesehatan fisik pada remaja ini sering diabaikan sehingga berdampak terhadap kesehatan fisik pada remaja.Kurangnya pengetahuan tentang personal hygiene dapat menjadi faktor pengehambat kesehatan kebersihan diri pada remaja.Ada beberapa bagian kesehatan yang perlu mendapat perhatian oleh remaja dalam pelaksanaan personal hygiene seperti, menjaga kesehatan gigi dan mulut, kesehatan kulit dan wajah, kesehatan organ reproduksi, pakaian seharihari, dan perawatan pada rambut serta kuku dan kaki.

Masalah lain yang dialami oleh remaja yaitu masalah kesehatan gigi dan mulut merupakan hal penting untuk kesehatan secara umum dan kualitas hidup, terutama pada remaja. Kesehatan mulut berarti terbebas kanker tenggorokan, infeksi dan luka pada mulut, penyakit gusi, kerusakan gigi, kehilangan gigi, dan penyakit lainnya, sehingga terjadi gangguan yang membatasi dalam menggigit, mengunyah, tersenyum, berbicara, dan kesejahteraan psikososial (WHO, 2012). Di Indonesia, hasil Survei Riset Kesehatan Dasar tahun 2013, antara lain: prevalensi penduduk yang mempunyai masalah gigimulut adalah $23,4 \%$, penduduk yang telah kehilangan seluruh gigi aslinya adalah $1,6 \%$, prevalensi nasional karies aktif adalah $43,4 \%$, dan penduduk dengan masalah gigi-mulut dan menerima perawatan atau pengobatan dari tenaga kesehatan gigi adalah $29,6 \%$ (Persatuan Dokter Gigi Indonesia, 2013).

Pada saat menstruasi Badan terasa kurang segar, karena tubuh memproduksi lebih banyak keringat dan minyak serta cairan tubuh lainnya. Pembalut tidak boleh dipakai lebih dari enam jam atau harus diganti sesering mungkin bila sudah dipenuhi oleh darah menstruasi. (Eny, 2011:24)

Angka kejadian infeksi pada organ reproduksi dapat dilihat dari data WHO diperkirakan 15 dari 20 remaja putri pernah mengalami keputihan setiap tahunnya. Infeksi tersebut disebabkan karena kurangnya kebersihan diri,terutama vulva higyne saat menstruasi. Data penelitian tentang kesehatan reproduksi wanita menunjukkan bahwa $75 \%$ wanita Indonesia pernah mengalami menstruasi dan pernah mengalami infeksi berupa keputihan abnormal dan 1 kali serangan infeksi jamur pada vagina wanita (Bkkbn, 2011). Sedangkan hasil penelitian dari Widyanto (2014) Kota Surabaya diketahui bahwa 67\% remaja telah dapat melakukan perawatan organ reproduksi eksternal (vulva).

Perawatan organ reproduksi sangatlah penting.Jika tidak dirawat dengan benar, makan dapat menyebabkan berbagai macam akibat yang dapat merugikan, misalnya infeksi.Cara pemeliharaan dan perawatan dapat dilakukan menurut agama, budaya, maupun medis.Cara pemeliharaan dan perawatan alat reproduksi ini sesuai dengan jenis kelamin, tetapi juga ada yang bersifat umum. (Eny, 2011:23)

\section{Metode}

Penelitian ini merupakanpenelitian Deskriptif dengan Pendekatan Crosssectional.Populasi dalam penelitian ini adalah semua remaja putri kelas VII A dan B dengan menggunakan teknik total sampling didapatkan sampel sejumlah 37 responden. 
Hasil

1) Karakteristik Responden Berdasarkan Umur

\begin{tabular}{clcc}
\hline No. & Umur(tahun) & $\mathbf{f}$ & $\mathbf{( \% )}$ \\
1. & 11 tahun & 0 & 0 \\
2. & 12 tahun & 10 & 27 \\
3. & 13 tahun & 27 & 73 \\
& Jumlah & 37 & 100 \\
\hline
\end{tabular}

Berdasarkan Tabel diatas dari 37 responden mayoritas berusia 13 Tahun (73\%)

2) Karakteristik Responden Berdasarkan Ruang Kelas

\begin{tabular}{cccc}
\hline No. & Ruang Kelas & f & $(\boldsymbol{\%})$ \\
1. & A & 21 & 57 \\
2. & B & 16 & 43 \\
\multicolumn{2}{r}{ Jumlah } & 37 & 100 \\
\hline
\end{tabular}

Berdasarkan Tabel dari 37 responden Mayoritas

berasal dari KelasA 21 Responden (57\%)

3) Karakteristik Responden Berdasarkan Tempat Tinggal

\begin{tabular}{llcc}
\hline No. & Tempat Tinggal & f & $\mathbf{( \% )}$ \\
1. & Orang tua & 35 & 94,5 \\
2. & Kos & 2 & 5,5 \\
& $\quad$ Jumlah & 37 & 100 \\
\hline
\end{tabular}

Berdasarkan Tabel dari 37 responden Mayoritas bertempat tinggal di rumah Orang Tua sebanyak 35 Responden $(94,5 \%)$

4) Karakteristik Responden Berdasarkan Pernah Mendapat Informasi

\begin{tabular}{|c|c|c|c|}
\hline No. & Mendapat Informasi & $\mathbf{f}$ & $(\%)$ \\
\hline 1. & Sudah pernah & 35 & 94,5 \\
\hline 2. & Belum pernah & 2 & 5,5 \\
\hline & Jumlah & 37 & 100 \\
\hline
\end{tabular}




\begin{tabular}{llcc}
\hline No. & Sumber Informasi & $\mathbf{f}$ & $\mathbf{( \% )}$ \\
1. & Orang tua & 14 & 40 \\
2. & Teman & 0 & 0 \\
3. & Guru & 5 & 14,3 \\
4. & Tenaga medis & 13 & 37,2 \\
5. & Media massa & 3 & 8,5 \\
& Jumlah & 35 & 100 \\
\hline
\end{tabular}

Berdasarkan Tabel dari 35 responden, Mayoritas mendapatkan Informasi tentang ersonal Hygiene dari Orang Tua sebanyak 14 (40\%)

\section{5) Karakteristik Responden}

\section{Berdasarkan Sumber Informasi}

\section{6) Gambaran Pengetahuan Remaja Putri Kelas VIIA dan B Tentang Personal Hygiene di SMPN 2 Mojo Kabupaten Kediri}

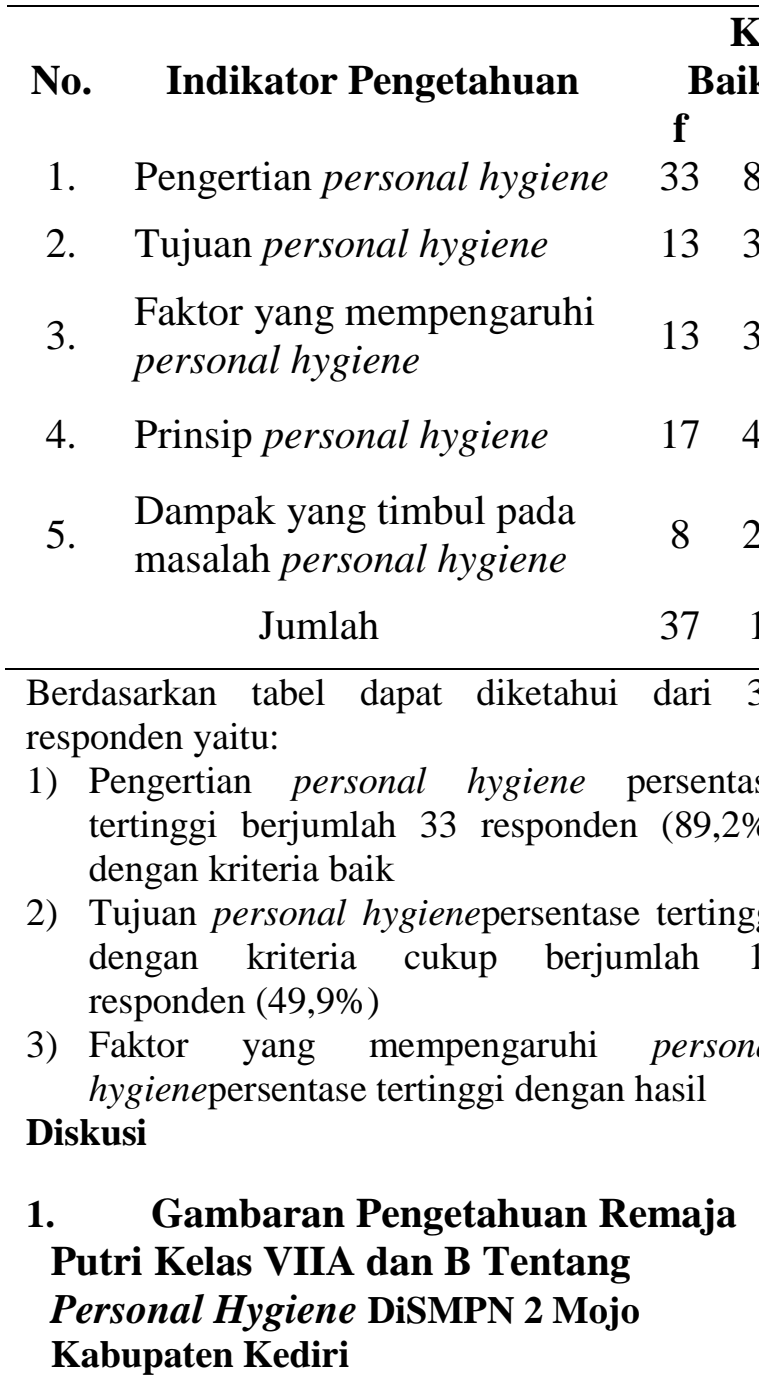

Berdasarkan hasil penelitian yang telah tercantum pada tabel IV.6 didapatkan 16 responden $(43,2 \%)$ memiliki pengetahuan 
baik, dan 21 responden $(56,8 \%)$ memiliki pengetahuan cukup. Hasil penelitian ini menunjukkan bahwa pengetahuan remaja putri kelas VII A dan B tentang personal hygiene dalam kategori cukup.

baik dan nyaman yang berkembang sebagai upaya untuk memenuhi kebutuhan manusia baik dimasa sekarang maupun dimasa depan. Sedangkan menurut Wawan\&Dewi (2011:18) dikatakan pengetahuan cukup dapat diketahui dan diinterpretasikan dengan skala yang bersifat kualitatif, kriteria cukup dengan hasil presentase $56 \%-75 \%$.

Berdasarkan data diatas remaja mempunyai pengetahuan tentang personal hygiene cukup, sedangkan pengetahuan tentang personal hygiene sendiri merupakan hal yang penting bagi remaja terutama pada remaja putri yang sudah memasuki masa pubertas yang sudah mengalami menstruasi dan perubahan bentuk tubuh.Personal hygiene harus lebih diperhatikan, untuk mencegah masuknya kuman kedalam tubuh dan mencegah timbulnya infeksi, sehingga pengetahuan tentang personal hygiene bagi remaja putri perlu ditingkatkan dengan cara memberikan penyuluhan dan konseling hal ini bisa dilakukan oleh Guru BK.

Berdasarkan hasil penelitian yang tercantum pada tabel IV.1, terdapat responden umur 12 tahun sejumlah 10 responden (27\%) dan umur 13 tahun sejumlah 27 responden (73\%). Hal ini menunjukkan bahwa sebagian besar responden berumur 13 tahun yaitu sejumlah 27 responden $(73 \%)$.

Menurut Wawan\&Dewi (2011:16) usia adalah umur individu yang terhitung mulai saat dilahirkan sampai berulang tahun. Sedangkan menurut Huclok (1998) Semakin cukup umur, tingkat kematangan dan kekuatan seseorang akan lebih matang dalam berfikir dan bekerja. Dari segi kepercayaan masyarakat seseorang yang lebih dewasa dipercayai dari orang yang belum tinggi kedewasaannya. Hal ini akan sebagai dari pengalaman dan kematangan jiwa.

Berdasarkan fakta diatas, peneliti berpendapat bahwa pengetahuan seseorang
Menurut Ariani (2014:7) Pengetahuan (knowledge) merupakan hasil rasa keingintahuan manusia terhadap sesuatu dan hasrat untuk meningkatkan harkat hidup sehingga kehidupan menjadi lebih dipengaruhi oleh beberapa faktor salah satunya yaitu umur. Umur mempengaruhi pengetahuan sesorang, semakin tinggi umur seseorang maka pengetahuan yang didapat akan semakin banyak, hal ini berkaitan dengan pengalaman pribadi yang telah dialami oleh seseorang, sehingga tidak ada batasan umur untuk memperoleh suatu pengetahuan.

Dari hasil kuesioner yang diisi oleh responden pada indikator pengetahuan tentang faktor yang mempengaruhi personal hygiene pada soal nomor 7 dengan pernyataan negatif yaitu kebiasaan gaya hidup seseorang tidak mempengaruhi personal hygiene, 27 responden $(75 \%)$ menjawab benar.

Menurut Yuni (2015:13) setiap orang memiliki keinginan individu dan pilihan tentang kapan untuk mandi, bercukur, dan melakukan perawatan tubuh lainnya.Sedangkan menurut Tarwoto\&Wartonah (2015:125) ada kebiasaan orang yang menggunakan produk tertentu dalam perawatan diri, seperti penggunaan sabun, shampoo, dan lain sebagainya.

Berdasarkan hasil diatas peneliti berpendapat bahwa ada beberapa faktor yang mempengaruhi personal hygiene salah satunya yaitu faktor kebiasaan seseorang. Kebiasaan seseorang dapat menentukan perilaku yang akan dilakukan, ada kebiasaan positif yang akan menghasilkan perilaku positif, dan ada kebiasaan negatif yang akan menghasilkan perilaku negatif. Kebiasaan dapat dijadikan sebagai pengalaman, sehingga kebiasaan perlu diperhatikan dalam hal menjaga kebersihan diri (personal hygiene) untuk meningkatkan pengetahuan yang positif.

Berdasarkan hasil dari kuesioner yang telah diisi oleh responden pada indikator pengetahuan tentang prinsip pelaksanaan 
personal hygiene pada soal nomor 16 dengan negatif yaitu pemilihan pembalut pada saat menstruasi tidak termasuk dalam perawatan personal hygiene, sebagian besar responden menjawab dengan benar yaitu sejumlah 30 responden $(80 \%)$.

Menurut Depkes (2012:53) pada saat haid, remaja putri harus memakai pembalut wanita yang bersih.Pilih pembalut yang tidak menjelang haid dan mulai terasa adanya keputihan yang sifatnya fisiologis, bisa menggunakan pembalut yang berukuran kecil (pantyliner).

Peneliti berpendapat bahwa kebersihan diri pada saat menstruasi harus lebih diperhatikan, seperti mandi minimal 2 kali sehari dan membersihkan organ genetalia pada saat mandi dan setelah buang air besar maupun buang air kecil, mengganti pembalut 3-4 kali sehari, pemilihan pembalut pada saat menstruai juga harus diperhatikan, untuk mencegah timbulnya alergi dan iritasi pada organ genetalia eksterna apabila tidak cocok pemakaiannya, menggunakan pembalut yang sekali pakai dan sebelum dibuang dicuci terlebih dahulu.

Berdasarkan hasil dari kuesioner yang telah diisi oleh responden pada indikator pengetahuan tentang dampak yang timbul dalam masalah personal hygiene pada soal nomor 17 dengan pernyataan positif yaitu timbulnya jerawat dapat mempengaruhi rasa percaya diri pada remaja putri, sebagian besar responden menjawab dengan benar yaitu berjumlah 29 responden (78\%).

\section{Simpulan}

Pentingnya peningkatan pengetahuan remaja putri pada personal hygiene dengan tepat agar tidak terkena infeksi, agar tidak terjadi sikap yang salah dalam melakukan personal hygiene sebaiknya perlu adanya pemberian informasi, misalnya penyuluhan tentang pentingnya personal hygiene dan penyuluhan tentan sikap dalam melakukan personal hygiene sehingga remaja putri paham apa itu personal hygiene, dan mampu pernyataan

berwarna dan tidak mengandung pewangi.Hal ini dilakukan untuk mengurangi paparan zat kimia pada vulva.Setelah buang air kecil atau air besar, ganti dengan pembalut yang baru.Jenis ukuran pembalut disesuaikan dengan kebutuhannya, misalnya pada

saat

Menurut Dingwall (2013:253) masalah jerawat pada remaja membawa dampak ketidaknyamanan social dan keinginan untuk diterima, karena jerawat dapat menyebabkan penurunan harga diri dan peningkatan kesadaran diri.Sedangkan menurut Yuni (2015:147) wajah merupakan bagian yang paling sensitive bagi serorang remaja terutama remaja putri, masalah jerawat pada remaja terkait dengan penampilan mereka.

Berdasarkan hasil penelitian, peneliti berpendapat bahwa ada beberapa dampak yang timbul dalam permasalahan personal hygiene salah satunya yaitu timbulnya jerawat pada remaja putri dapat mempengaruhi rasa percaya diri.Pada masa awal pubertas kebanyakan remaja mengalami timbulnya jerawat, hal ini bisa diakibatkan oleh perubahan fisik maupun psikologis yang merupakan salah satu tanda pubertas bagi remaja awal.Pada umumnya remaja putri menjadi tidak percaya diri akibat timbulnya jerawat, hal ini juga mempengaruhi penampilan pada remaja yang minder akibat timbulnya jerawat pada wajah.

$$
\begin{aligned}
& \text { bersikap secara tepat dalam melakukan } \\
& \text { personal hygiene. }
\end{aligned}
$$

.Daftar Pustaka

Ariani, A, 20014.Aplikasi Metodologi Penelitian Kebidanan Dan Kesehatan Reproduksi.Yogyakarta : Nuha Medika. 
Azwar, S, 2011, Sikap Manusia Teori Dan Pengukuran, $2^{\text {rd }}$ ed. Yogyakarta : Pustaka Pelajar

Budiman \& Riyanto, A, 2014.Kapita Selekta Kuesioner Pengetahuan dan Sikap dalam Penelitian Kesehatan.Jakarta : Salemba Medika.

Dingwall, L. 2013. Personal Hygiene Care : Essential Clinical Skills For Nurses. Jakarta : EGC

Donsu, J, 2016. Metodologi Penelitian Keperawatan..Yogyakarta Pustakabarupress.

Hidayat, A, 2010.Metode Penelitian Kebidanan Teknik Analisa Data.Jakarta : Salemba Medika.

Kusmiran, E, 2011. Kesehatan Reproduksi Remaja dan Wanita.Jakarta : Salemba Medika.

Nursalam, 2014.Metodologi Penelitian Ilmu Keperawatan. $3^{\text {rd }}$ ed. Jakarta : Salemba Mendika.

Notoadmodjo, S, 2012. Metodologi Penelitian Kesehatan. Jakarta : Rineka Cipta.

Pinem, S, 2009. Kesehatan Reproduksi dan Kontrasepsi.Jakarta : TIM.

Poltekkes Depkes Jakarta 1, 2012.Kesehatan Remaja Problem dan Solusinya.Jakarta : Salemba Medika.

Riyanto, A, 2017.Aplikasi Metodologi Penelitian Kesehatan.Yogyakarta : Nuha Medika.

Rohan, H., Setyowati, A., Herdyana, E., Komariyah, S \& Agustina, E. 2016.Buku Kesehatan Reproduksi. Malang : Intimedia.

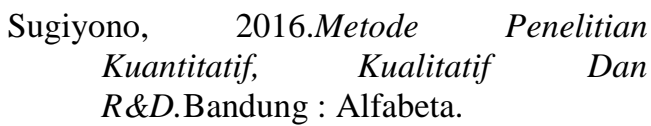

Saryono \& Widianto, W 2011.Catatan Kuliah Kebutuhan Dasar Manusia (KDM). Yogyakarta : Nuha Medika.
Tarwoto \& Wartonah, 2015.Kebutuhan Dasar Manusia dan Proses Keperawatan - Edisi 5.Jakarta : Salemba.

Wawan \& Dewi, 2011. Teori Dan Pengukuran Pengetahuan, Sikap Dan Perilaku Manusia. Yogyakarta : Nuha Medika.

Yuni, N, 2015. Buku Saku Personal Hygiene.Yogyakarta : Nuha Medika.

Febryary, A., Astuti, S \& Hartinah. 2016. Gambaran Pengetahuan, Sikap dan Perilaku Remaja Putri dalam Penanganan Keputihan di Desa Ciliyung [online] Diakses dari Error! Hyperlink reference not valid. [Diakses pada 3 Maret 2018]

Cahyono\&Noeraini. 2016. Pengetahuan Remaja Putri Tentang Personal Hygiene Saat Menstruasi [online] Diakses dari Error! Hyperlink reference not valid. [Diakses pada 1 Maret 2018]

Gustina\&Djannah. 2014. Jurnal Kesehatan Masyarakat [online] Diakses dari Error! Hyperlink reference not valid.[Diakses pada 2 Maret 2018].

Karnita, R, 2014. Gambaran Pengetahuan dan Sikap Remaja Putri Tentang Personal Hygiene Organ Reproduksi [online] Diakses dari http:// Pengetahuan\%20dan\%20sikap\%20rem aja\%20tentang\%20PH.pdf [Diakses pada 1 Maret 2018]

SDKI. 2012. Kesehatan Reproduksi Remaja [online] Diakses dari http://PDF/SDKI-2012-RemajaIndonesia.pdf [Diakses pada 27 Februari 2018].

Purwandari, R., Ardiana, A., Wantiyah. 2013. Hubungan Antara Perilaku Mencuci Tangan Dengan Insiden Diare Pada Anak Usia Sekolah[online] Diakses dari Error! Hyperlink reference not valid. [Diakses pada 9 Maret 2018]

Widayati, N. 2014.Faktor yang berhubungan dengan karies gigi pada anak [online] Diakses dati http://175-233-1-SM.pdf [Diakses pada 9 Maret 2018] 
